\title{
The frequency and effect of fibromyalgia in patients with Behçet's disease
}

\author{
Murat Toprak, ${ }^{1}$ Metin Erden, ${ }^{2}$ Mahmut Alpayc1, ${ }^{1}$ Levent Ediz, ${ }^{1}$ Levent Yazmalar, ${ }^{3}$ Özcan Hız, ${ }^{4}$ İbrahim Tekeoğlu ${ }^{5}$ \\ ${ }^{1}$ Department of Physical Medicine and Rehabilitation, Medical Faculty of Yüzüncü Yll University, Van, Turkey \\ ${ }^{2}$ Department of Physical Medicine and Rehabilitation, Van Training and Research Hospital, Van, Turkey \\ ${ }^{3}$ Department of Physical Medicine and Rehabilitation, Medical Faculty of Dicle University, Diyarbakır, Turkey \\ ${ }^{4}$ Department of Physical Medicine and Rehabilitation, Medical Park Hospital, Ordu, Turkey \\ ${ }^{5}$ Department of Physical Medicine and Rehabilitation, Medical Faculty of Sakarya University, Sakarya, Turkey
}

Received: March 2016 Accepted: June 2016

\begin{abstract}
Objectives: This study aims to investigate the scores of depression, anxiety, sleep and quality of life (QoL), to identify the prevalence of fibromyalgia (FM) in Behçet's disease (BD), and to evaluate whether there is a difference between BD patients with and without FM in these scores.

Patients and methods: Between March 2008 and January 2009, 97 patients with BD and 95 age- and sex-matched healthy controls were included in the study. The patients with BD were divided into two groups according to the presence or absence of FM. All participants were evaluated by the Beck Depression Inventory (BDI), Beck Anxiety Inventory (BAI), Pittsburgh Sleep Quality Index (PSQI), and Medical Outcomes Study Short Form-36 (SF-36).

Results: Compared to the controls, FM prevalence was higher (19.6\% vs 3.2\%) with increased BDI and BAI scores, while the subscores of SF-36 including physical function, physical role, pain, general health, social function, and emotional role decreased in BD patients (for all $\mathrm{p}<0.001$ ). All BD patients with FM were females ( $n=19)$, while only $46 \%$ of BD patients without FM were females $(n=36)(p<0.001)$. In $B D$ patients with FM, compared to female BD patients without FM, the mean age $(\mathrm{p}=0.017)$, disease duration $(\mathrm{p}=0.028)$, and BDI scores $(\mathrm{p}=0.017)$ were significantly higher, while the PSQI scores ( $\mathrm{p}=0.001)$ and SF-36 subscores, except general health $(\mathrm{p}=0.114)$, were significantly lower (for all $\mathrm{p}<0.05)$.

Conclusion: Our study results suggest that patients with BD have an increased severity of depression and anxiety, higher frequency of FM, and worsened QoL than healthy individuals. In addition, the presence of FM seems to be related with female sex, longer disease duration, older age, depression, sleep disturbance, and poor QoL in BD patients.
\end{abstract}

Keywords: Behçet's disease; fibromyalgia; prevalence; quality of life.

Fibromyalgia (FM) is a chronic disorder characterized by widespread musculoskeletal pain accompanied by fatigue, sleep disturbance, and psychiatric issues such as depression and anxiety. ${ }^{[1]}$ Behçet's disease (BD) is a systemic vasculitis which manifests with recurrent oral and genital ulcerations, skin lesions, uveitis, and central nervous system and gastrointestinal involvement. ${ }^{[2]}$ Currently, the etiological factors of both FM and BD are still exactly unknown, although has been proposed that both diseases are caused by a combination of genetic and environmental risk factors. ${ }^{[1,2]}$ While the association between FM and sleep disturbance, psychiatric problems and poor quality of life (QoL) is well-known, this possible association for $\mathrm{BD}$ has not yet been fully investigated. In addition, a relationship between FM and some rheumatic diseases, such as primary Sjögren's syndrome (pSS), rheumatoid arthritis (RA), and systemic lupus erythematosus (SLE), has been found ${ }^{[3]}$ however, there is a limited number of data on the relationship between FM and BD.

In the present study, therefore, we aimed to investigate the scores of depression, anxiety, sleep and QoL, to identify the prevalence of FM in BD, and to evaluate whether there is a difference between $\mathrm{BD}$ patients with and without FM in these scores. 


\section{PATIENTS AND METHODS}

Between March 2008 and January 2009, a total of 97 consecutive patients with BD who were diagnosed according to the criteria of the International Study Group for $\mathrm{BD}^{[4]}$ and 95 age- and sex-matched healthy controls were included in this study. The patients with $\mathrm{BD}$ were divided into two subgroups according to the presence $(n=19)$ or absence of FM $(n=78)$. Since there were no male BD patients with FM, only patients with $\mathrm{BD}$ and FM $(\mathrm{n}=19)$ and female BD patients without FM $(n=36)$ were included in the statistical analysis. Therefore, a possible sex effect on the results was eliminated thanks to this analysis. The participants who had other rheumatic disease, infections, liver or renal disorder, systemic diseases (e.g. diabetes mellitus, hyper- or hypothyroidism, asthma, etc.) were excluded from the study.

The diagnosis of FM was performed according to the American College of Rheumatology criteria. ${ }^{[5]}$ The study protocol was approved by the Ethics Review Board of the Yüzüncü Yıl University Hospital. A written informed consent was obtained from each participant. The study was conducted in accordance with the principles of the Declaration of Helsinki.

All participants were evaluated by the Beck Depression Inventory (BDI), ${ }^{[6]}$ Beck Anxiety Inventory (BAI), ${ }^{[7]}$ Pittsburgh Sleep Quality Index (PSQI), ${ }^{[8]}$ and
Medical Outcomes Study Short Form-36 (SF-36). ${ }^{[9]}$ The Turkish validity and reliability studies of these questionnaires were carried out by Hisli, ${ }^{[6]}$ Ulusoy et al., ${ }^{[7]}$ Ağargün et al., ${ }^{[8]}$ and Koçyiğit et al. ${ }^{[9]}$

\section{Statistical analysis}

Statistical analysis was performed using the SPSS version 16.0 software (SPSS Inc., Chicago, IL, USA). Descriptive data were expressed in mean \pm standard deviation, median, min-max and $\mathrm{n}(\%)$. The Student's t-test and Mann-Whitney $U$ tests were performed to compare the continuous variables. The chi-square or Fisher's exact test was used to compare the distributions of the categorical variables. A $p$ value of $<0.05$ was considered statistically significant.

\section{RESULTS}

The age and sex characteristics of patients with $\mathrm{BD}$ and healthy controls were similar. However, there were significant differences in the BDI, BAI, SF-36 physical function, physical role, pain, general health, social function, and emotional role scores between the patient and control groups (for all $\mathrm{p}<0.001$ ). On the other hand, the PSQI, SF-36 vitality, and SF-36 mental health scores were not found to be different between these groups ( $\mathrm{p}=0.930 ; \mathrm{p}=0.120$; and $\mathrm{p}=0.074$, respectively). Among 97 patients with BD, 19 (20.6\%)

Table 1. A comparison between patients of Behçet's disease and the healthy controls

\begin{tabular}{|c|c|c|c|c|c|c|c|c|c|c|c|}
\hline & \multicolumn{5}{|c|}{ BD patients $(\mathrm{n}=97)$} & \multicolumn{5}{|c|}{ Healthy controls $(\mathrm{n}=95)$} & \multirow[b]{2}{*}{$p$} \\
\hline & $\mathrm{n}$ & $\%$ & Mean \pm SD & Median & Min-Max & $\mathrm{n}$ & $\%$ & Mean \pm SD & Median & Min-Max & \\
\hline Age (year) & & & & & & & & & & & 0.985 \\
\hline$<20$ & 11 & 11.3 & & & & 11 & 11.6 & & & & \\
\hline $20-45$ & 74 & 76.3 & & & & 73 & 76.8 & & & & \\
\hline$\geq 45$ & 12 & 12.4 & & & & 11 & 11.6 & & & & \\
\hline Sex & & & & & & & & & & & 1.000 \\
\hline Female & 55 & & & & & 54 & & & & & \\
\hline Male & 42 & & & & & 41 & & & & & \\
\hline BDI & & & $18.3 \pm 11.0$ & & & & & $10.9 \pm 8.3$ & & & $<0.001$ \\
\hline BAI & & & & 21 & $0-54$ & & & & 9 & $0-43$ & $<0.001$ \\
\hline PSQI & & & $7.1 \pm 3.6$ & & & & & $7.1 \pm 3.4$ & & & 0.930 \\
\hline \multicolumn{12}{|l|}{ SF-36 } \\
\hline Physical function & & & $52.8 \pm 25.8$ & & & & & $77.2 \pm 20.4$ & & & $<0.001$ \\
\hline Physical role & & & & 25 & $0-100$ & & & & 100 & $0-100$ & $<0.001$ \\
\hline Pain & & & $40.9 \pm 26.0$ & & & & & $62.4 \pm 25.7$ & & & $<0.001$ \\
\hline General health & & & $39.6 \pm 19.0$ & & & & & $56.8 \pm 21.8$ & & & $<0.001$ \\
\hline Vitality & & & $46.0 \pm 19.4$ & & & & & $49.9 \pm 15.9$ & & & 0.129 \\
\hline Social function & & & & 50 & $0-100$ & & & & 75 & $25-100$ & $<0.001$ \\
\hline Emotional role & & & & 33 & $0-100$ & & & & 100 & $0-100$ & $<0.001$ \\
\hline Mental health & & & $54.6 \pm 19.1$ & & & & & $59.4 \pm 17.4$ & & & 0.074 \\
\hline FM frequency & 19 & 19.6 & & & & 3 & 3.2 & & & & $<0.001$ \\
\hline
\end{tabular}

BD: Behçet's disease; SD: Standard deviation; Min: Minimum; Max: Maximum; BDI: Beck Depression Inventory; BAI: Beck Anxiety Inventory; PSQI: Pittsburgh Sleep Quality Index; SF-36: Short Form-36; FM: Fibromyalgia. 
Table 2. A comparison between Behçet's disease patients with and without fibromyalgia

\begin{tabular}{|c|c|c|c|c|c|c|c|}
\hline & \multicolumn{3}{|c|}{ Behçet's disease with FM $(\mathrm{n}=19)$} & \multicolumn{3}{|c|}{ Behçet's disease without FM $(n=36)$} & \multirow[b]{2}{*}{$p$} \\
\hline & $\mathrm{n}$ & Median & Min-Max & $\mathrm{n}$ & Median & Min-Max & \\
\hline Age (year) & & 37 & $26-45$ & & 30.5 & $24-42$ & 0.017 \\
\hline \multicolumn{8}{|l|}{ Sex } \\
\hline Female & 19 & & & 36 & & & \\
\hline Male & 0 & & & 0 & & & \\
\hline Disease duration (years) & & 7 & $3-13$ & & 5 & $1-13$ & 0.028 \\
\hline Beck Depression Inventory & & 24 & $13-49$ & & 14 & $2-45$ & 0.017 \\
\hline Beck Anxiety Inventory & & 20 & $7-52$ & & 21 & $0-48$ & 0.390 \\
\hline Pittsburgh Sleep Quality Index & & 10 & $5-16$ & & 6 & $2-14$ & 0.001 \\
\hline \multicolumn{8}{|l|}{ Short Form-36 } \\
\hline Physical function & & 40 & $20-90$ & & 50 & $0-100$ & 0.015 \\
\hline Physical role & & 0 & $0-100$ & & 50 & $0-100$ & 0.001 \\
\hline Pain & & 22 & $0-54$ & & 46 & $0-100$ & 0.006 \\
\hline General health & & 40 & $5-67$ & & 45 & $0-90$ & 0.114 \\
\hline Vitality & & 30 & $0-55$ & & 50 & $20-95$ & $<0.001$ \\
\hline Social function & & 50 & $0-100$ & & 62 & $12-100$ & 0.015 \\
\hline Emotional role & & 0 & $0-33$ & & 33 & $0-100$ & $<0.001$ \\
\hline Mental health & & 40 & $20-88$ & & 56 & $24-100$ & 0.003 \\
\hline
\end{tabular}

FM: Fibromyalgia; SD: Standard deviation; Min: Minimum; Max: Maximum.

fulfilled the criteria for the diagnosis of FM, while only three of the 95 healthy controls (3.1\%) met the ACR criteria for FM $(\mathrm{p}<0.001)$ (Table 1$)$.

All BD patients with FM were females, while the female ratio for BD patients without FM was only $46 \%$ $(p<0.001)$. There were statistically higher values in BD patients with FM $(n=19)$ than female BD patients without FM $(n=36)$ in terms of age $(p=0.017)$ and disease duration $(\mathrm{p}=0.028)$. The patients with both $\mathrm{BD}$ and FM scored significantly higher in the BDI $(\mathrm{p}<0.017)$ and PSQI $(\mathrm{p}=0.001)$, and scored significantly lower in the SF-36 components, except general health $(\mathrm{p}=0.114)$, compared to the patients with only $\mathrm{BD}$ (for all $\mathrm{p}<0.05)$ (Table 2).

\section{DISCUSSION}

In this study, we evaluated the status of depression, anxiety, sleep quality, and health-related QoL in patients with BD using the BDI, BAI, PSQI, and SF-36 questionnaires. We found significantly higher scores in depression and anxiety and significantly lower scores in the health-related QoL and also significantly higher frequency of FM in patients with BD than in healthy controls. Also, we found higher frequency of FM in patients with $\mathrm{BD}$ than in healthy controls. However, there was no significant difference in the PSQI scores between BD patient and healthy control groups. These results suggest that $\mathrm{BD}$ may be associated with anxiety, depression, and poor QoL, but not with sleep disturbance. In addition, BD patients with FM had significantly higher values than $\mathrm{BD}$ patients without
$\mathrm{FM}$ in terms of female/male ratio, disease duration, age, BDI, PSQI, and SF-36. However, there was no significant difference in the BAI scores between these subgroups. These results indicate that FM in BD may be associated with female sex, longer disease duration, older age, depression, sleep disturbance, and poor QoL, but not with anxiety.

There is only a limited number of studies in the literature investigating the status of depression, anxiety, sleep disturbance and QoL in BD. Previous studies have reported an increase in the severity of depression and anxiety in patients with $\mathrm{BD}$, compared to healthy individuals. ${ }^{[10]}$ In addition, studies focusing on the effect of BD on sleep disturbance and QoL found that patients with BD have reduced sleep quality and QoL. ${ }^{[1-13]}$ The findings from the present study are consistent with previous studies for the evolution of depression, anxiety, and QoL in the patients with $\mathrm{BD}$. A significant role of emotional dysfunction was also shown in the course of rheumatic diseases such as BD. It is possible that some increased proinflammatory cytokines in $\mathrm{BD}$, such as interleukin-1 $\beta$, interleukin-8, and tumor necrosis factor-alpha, affect the neuroendocrine activity and neurotransmitter systems, thereby, leading to predisposition to the development of emotional issues. ${ }^{[13]}$ In our study, however, we found no significant difference in the sleep quality between $\mathrm{BD}$ patients and healthy controls.

Review of the literature on the possible association between FM and BD yields limited data. To date, only five studies investigated the prevalence of FM 
in patients with $\mathrm{BD}$, and all of these studies reported significantly higher rates of FM in BD patients, compared to healthy controls. ${ }^{[14-18]}$ However, only one of these studies investigated the effect of FM on depression and anxiety, and they found that FM was associated with anxiety and depression in $\mathrm{BD}^{\left[{ }^{[16]}\right.} \mathrm{In}$ our study, we found significant difference between BD patients with and without FM in terms of depression scores, although there was no significant difference in the anxiety scores. In addition, we found that the mean age and disease duration were significantly higher in BD patients with FM. These findings are inconsistent with the findings of Lee et al. ${ }^{[16]}$ and Melikoglu and Melikoglu ${ }^{[17]}$ which indicated no significant difference in the age and disease duration between BD patients with and without FM. However, BD patients with FM were more frequently females in their cohort. This sex ratio-related finding is consistent with our study which included only female BD patients with FM.

Furthermore, we demonstrated poorer QoL in BD patients with FM, compared to $\mathrm{BD}$ patients without FM. To the best of our knowledge, this is the second study to investigate the effect of FM on the QoL in patients with $\mathrm{BD}$. In a recent study, Garip et al. ${ }^{[18]}$ reported that FM was associated with higher disease activity and poorer QoL in BD patients.

Furthermore, some possible mechanisms which can explain the increased prevalence of FM among patients with BD should be taken into account. Although the main pathology of $\mathrm{BD}$ has been known to be the underlying vasculitis and the main pathology of FM has been shown to be the central sensitization, the etiology and exact pathogenesis of both diseases are still unclear. ${ }^{[19,20]}$ However, both genetic and environmental factors such as microbial pathogens have been proposed to initiate an immune dysfunction and dysfunction of pain sensation which cause development of the clinical manifestations of these diseases. ${ }^{[19-21]}$ In addition, a possible subclinical damage to the peripheral nerves due to systemic vasculitis may be associated with neuropathic pain in BD patients having long disease duration. In addition, it is quite common for patients with rheumatic diseases, such as RA, SLE, and pSS to also have FM. ${ }^{[3]}$ A possible effect of immune dysregulation and proinflammatory cytokines has been suggested as a precipitating factor for the development of FM in rheumatic diseases. ${ }^{[18]}$ It is considered that $\mathrm{BD}$ is also a rheumatic disease and, possibly, FM is a component of immune dysfunctionmediated rheumatic disorders particularly in female patients.
It has been reported that there are some challenges in the diagnosis of chronic immunemediated rheumatic diseases and FM is a widespread and often underdiagnosed condition in patients with comorbidities or rheumatic diseases. ${ }^{[3,22]}$ The previous five studies investigating the prevalence of FM among BD patients reported significantly higher rates (8.9 to $37.1 \%) .^{[14-18]}$ Similarly, we found a high frequency $(19.6 \%)$ of $\mathrm{FM}$ in patients with $\mathrm{BD}$, and BD patients with FM had an increased severity of depression and anxiety and had reduced sleep and QoL than BD patients with FM. These results may be helpful to increase the awareness of clinicians to these coexistences and facilitate the diagnostic and therapeutic process.

On the other hand, this study has some limitations. First, evaluation of disease activity was unable to be done for both BD and FM. Second, a correlation analysis was unable to be performed to assess the association between the disease activity, clinical patterns, anxiety, depression, QoL, and sleep quality. Therefore, further comprehensive studies are needed to fully elucidate the relation between these conditions. Finally, although the PSQI was used for the assessment of sleep quality, a polysomnography assessment could have provided more reliable results.

In conclusion, our study results show an increased frequency of FM, higher scores of depression and anxiety, and reduced scores of QoL in BD patients, compared to healthy individuals. In addition, the occurrence of FM appears to be related to female sex, longer disease duration, older age, depression, sleep disturbance, and poor QoL in BD patients.

\section{Declaration of conflicting interests}

The authors declared no conflicts of interest with respect to the authorship and/or publication of this article.

\section{Funding}

The authors received no financial support for the research and/or authorship of this article.

\section{REFERENCES}

1. Giacomelli C, Sernissi F, Sarzi-Puttini P, Di Franco M, Atzeni F, Bazzichi L. Fibromyalgia: a critical digest of the recent literature. Clin Exp Rheumatol 2013;31:153-7.

2. Dalvi SR, Yildirim R, Yazici Y. Behcet's Syndrome. Drugs 2012;72:2223-41.

3. Atzeni F, Cazzola M, Benucci M, Di Franco M, Salaffi F, Sarzi-Puttini P. Chronic widespread pain in the spectrum of rheumatological diseases. Best Pract Res Clin Rheumatol 2011;25:165-71.

4. Criteria for diagnosis of Behçet's disease. International Study Group for Behçet's Disease. Lancet 1990;335:1078-80. 
5. Wolfe F, Smythe HA, Yunus MB, Bennett RM, Bombardier C, Goldenberg DL, et al. The American College of Rheumatology 1990 Criteria for the Classification of Fibromyalgia. Report of the Multicenter Criteria Committee. Arthritis Rheum 1990;33:160-72.

6. Hisli N. Beck Depresyon Envanteri'nin geçerliliği üzerine bir çalışma. Psikoloji Dergisi 1988;6:118-22.

7. Ulusoy M, Sahin NH, Erkmen H. Turkish Version of the Beck Anxiety Inventory: Psychometric Properties. J Cogn Psychother Int Q 1998;12:163-72.

8. Ağargün MY, Kara H, Anlar O. Pittsburgh Uyku Kalitesi indeksinin geçerliği ve güvenirliği. Türk Psikiyatri Derg 1996;7:107-15.

9. Koçyiğit H, Aydemir Ö, Fişek G, Ölmez N, Memiş A. Kısa Form-36 (KF-36)'nın Türkçe versiyonunun güvenilirliği ve geçerliliği. İlaç ve Tedavi Dergisi 1999;12:102-6.

10. Monastero R, Camarda C, Pipia C, Lopez G, Camarda LK, Baiamonte $\mathrm{V}$, et al. Cognitive impairment in Behçet's disease patients without overt neurological involvement. J Neurol Sci 2004;220:99-104.

11. Yazmalar L, Batmaz İ, Sarıyıldız MA, Yıldız M, Uçmak D, Türkçü F, et al. Sleep quality in patients with Behçet's disease. Int J Rheum Dis 2014 Sep 8. [Epub ahead of print]

12. Bodur H, Borman P, Ozdemir Y, Atan C, Kural G. Quality of life and life satisfaction in patients with Behçet's disease: relationship with disease activity. Clin Rheumatol 2006;25:329-33.

13. Koca I, Savas E, Ozturk ZA, Tutoglu A, Boyaci A, Alkan S, et al. The relationship between disease activity and depression and sleep quality in Behçet's disease patients.
Clin Rheumatol 2015;34:1259-63.

14. Yavuz S, Fresko I, Hamuryudan V, Yurdakul S, Yazici H. Fibromyalgia in Behçet's syndrome. J Rheumatol 1998;25:2219-20.

15. Al-Izzi MK, Jabber AS. Fibromyalgia in Iraqi patients with Behcet's disease. J Med Liban 2004;52:86-90.

16. Lee SS, Yoon HJ, Chang HK, Park KS. Fibromyalgia in Behçet's disease is associated with anxiety and depression, and not with disease activity. Clin Exp Rheumatol 2005;23:15-9.

17. Melikoglu M, Melikoglu MA. The prevalence of fibromyalgia in patients with Behçet's disease and its relation with disease activity. Rheumatol Int 2013;33:1219-22.

18. Garip Y, Guler T, Cifci N, Dörtbaş F, Karci AA. Impact of fibromyalgia syndrome on quality of life in patients with Behçet's disease. Turk J Phys Med Rehab 2016;62:45-50.

19. Bicer A. Musculoskeletal Findings in Behcet's Disease. Patholog Res Int 2012;2012:653806.

20. Noehren B, Dailey DL, Rakel BA, Vance CG, Zimmerman MB, Crofford LJ, et al. Effect of transcutaneous electrical nerve stimulation on pain, function, and quality of life in fibromyalgia: a double-blind randomized clinical trial. Phys Ther 2015;95:129-40.

21. Gezici E, Alpaycı M, Özkan Y, Küçük ME, Ünver H, $\mathrm{H} 1 \mathrm{z}$ Ö. The effects of Helicobacter pylori eradication on the number of tender points, sleep quality, depression, and anxiety in patients with fibromyalgia. Arch Rheumatol 2014;29:151-4.

22. Schirmer M, Duftner C, Dejaco C. Challenges in the diagnosis of chronic immune-mediated rheumatic diseases. Discov Med 2013;15:160-5. 